\title{
DIDACTIC METHODS USED IN SPORT FOR TRAINING CHILDREN AT RISK OF SOCIAL EXCLUSION
}

\author{
Alina Daniela MOANȚÄ ${ }^{1}$, Valentin CARACAȘ ${ }^{1}$, Sorin CIOLCĂ ${ }^{1}$, Doina CROITORU ${ }^{\mathbf{1}}$, \\ Iulian Gabriel GHIȚESCU ${ }^{1}$, Gheorghe GRIGORE ${ }^{1}$, Cezar HANTĂU ${ }^{1}$, Alin SĂFTEL ${ }^{1 *}$ \\ ${ }^{1}$ National University of Physical Education and Sport, Faculty of Physical Education and Sport, Bucharest, \\ Romania \\ *Corresponding author: mihaita.saftel@gmail.com
}

DOI: https://doi.org/10.51267/icpesk2020bp11

\begin{abstract}
In the complex process of training children at risk of social exclusion, sports activities with content from sports games aim at specific motor objectives related to the acquisition, strengthening or improvement of the knowledge, abilities and motor skills specific to each sport, as well as social objectives mainly aimed to facilitate integration into small, medium and large social groups of children. The effectiveness of the training is determined by the system of methods and means used, their variety, so that the practice of sports games determines multiple acquisitions, from the point of view of student communication, by increasing the number of specific motor skills, determining the proper organization and direction of the activity, stimulating and maintaining students' interest in the practice of sports games. The study aims to find the most useful methods and means of training children at risk of social exclusion by using a questionnaire survey. It was applied to teachers and specialist inspectors working with children included in the target group within the project "Sustainable social and educational integration through sports activities" - PNP001, which is in its first year of development. The information provided by the questionnaire survey and the conclusions of this study will lead to the optimisation of the methodology for intervention on the target group.
\end{abstract}

Keywords: method, exclusion, sports games.

\section{Introduction}

In the 2019-2023 period, the National University of Physical Education and Sport (UNEFS) in Bucharest, Romania, benefits from a grant offered by Iceland, Lichtenstein and Norway through the EEA (European Economic Area), and Norwegian grants from the Local Development Programme. The objective of this programme is to facilitate the educational and social integration of 2,600 middle-school children (grades 5-8) at risk of exclusion. They are selected from the 8 development regions of the country for integrated activities based on sport.

The project called "Sustainable social and educational integration through sports activities" addresses early school dropout. Based on previous studies, the main causes were identified as: unemployment, social exclusion, poverty and poor health. The approach is based on integrated outdoor sports activities.

This typology of methodological approach to social integration relies on activities with a highly-pronounced inclusive character and a substantial component based on increasing the levels of motivation and self-esteem. This innovative approach, which is backed by structural support measures meant to encourage long-term participation, is thought to be unitarily implemented at national level through this project. The project has a strategical approach at national level: the importance of sport for educational and social integration is highlighted by the Romanian Government in its policy and strategy documents as a priority measure of integration. 


\section{Context}

The statistical research methodology in the field of education developed by the National Institute of Statistics (INS) and published by the Ministry of Education and Research highlighted in the last centralised document important data regarding school dropout rates.

In this context, grade-based dropout rates are also relevant. The data show that the highest dropout rates are in the first grades of an educational level, namely the 1st, 2nd and 5th grades (Table 1, Figure 1).

Table 1. Average school dropout rates in primary education and middle school based on grades and residence, 2008-2015 (Source: Data calculated according to INS information, 2008-2016)

\begin{tabular}{lccccccc}
\hline Grade & $2008 / 2009$ & $2009 / 2010$ & $2010 / 2011$ & $2011 / 2012$ & $2012 / 2013$ & $2013 / 2014$ & $2014 / 2015$ \\
\hline $4^{\text {th }}$ & 1.3 & 1.2 & 1.4 & 1.4 & 1.3 & 1.3 & 1.4 \\
$5^{\text {th }}$ & 2.8 & 2.5 & 2.7 & 2.6 & 2.4 & 2.5 & 2.4 \\
$6^{\text {th }}$ & 1.6 & 1.5 & 1.8 & 1.7 & 1.4 & 1.6 & 1.7 \\
$7^{\text {th }}$ & 1.8 & 1.4 & 2.0 & 1.8 & 1.6 & 1.6 & 1.8 \\
$8^{\text {th }}$ & 1.5 & 1.3 & 1.4 & 1.7 & 1.5 & 1.5 & 1.6 \\
\hline
\end{tabular}

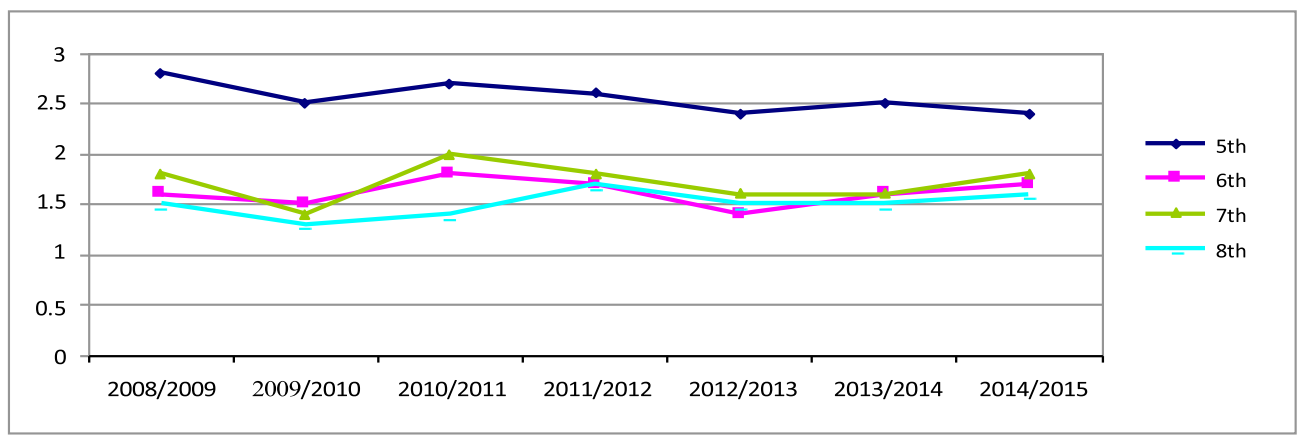

Figure 1. Grade-based dropout rates in middle school, 2008-2015

Based on the information received from the Ministry of Education and Research, the high school dropout rates at the beginning of an educational level are caused by the difficulties that students face in adapting to school demands and when changing an educational level: different teaching styles, more complex curricular requirements and significant differences in the number of weekly hours dedicated to study.

Throughout an educational level, a decrease in school dropout rates can be noted from the $5^{\text {th }}$ to $8^{\text {th }}$ grades. This is probably determined by the progressive adaptation of students to school demands.

\section{Social integration/ Reducing social exclusion}

Synthesising several points of view, Dragnea et al. (2006) consider physical education to be a component of general education, which is expressed through a type of physical activity (along with sports training, competition, outdoor activities, body language activities and recovery activities) carried out in an organized way, whose specifically designed content aims to 
optimise the individual's biological and motor performance, as well as cognitive, emotional and social components, thus leading to an increase in their quality of life.

Physical education addresses all people regardless of age, gender, professional training etc., including here people with disabilities. Physical education is important for these people because it helps them develop their abilities and supports their initiation into different sports, which enables them to satisfy their needs and interests and stay involved in the activity for a long period of time.

Several researchers and field specialists have studied different aspects of social integration or means of reducing social exclusion through sports activities for children who are in different types of risk situations, presenting ideas on which the present study is based. The findings of these studies support the means proposed for the activities in the current research.

The processes of integration and inclusion are usually approached in the research areas of psychology and sociology. However, more and more research can be noted in the context of sport. Sport is traditionally a space for creating networks, and its valence strength is recognized.

Marivoet (2014) highlights that there is a broad consensus at institutional level on the notions of "social inclusion in sport" and "inclusion through sport". Social inclusion in sport means the existence of equal opportunities of access. Social inclusion through sport refers to the development of traits that aim at promoting formative sport. In this case, the ethical principles and values of sport are related to the sport for children and young people in school or those at risk of discrimination.

Elling et al. (2001) also argue that social integration itself is a multidimensional process and distinguish three dimensions of integration (structural, social-cultural, social-affective), which can all occur in and through the practice of sport.

Generally, sport participation is widely advocated as an effective and unproblematic way for interethnic contact and socialisation (Krouwel et al., 2006). On the sport field, a common goal unites the participants. Mastering a skill is more important than any other individual trait.

Referring to multicultural societies, Hatzigeorgiadis et al. (2013) state that sport participation per se does not seem to have the power to achieve anticipated integration, but rather sport would provide a common ground where integration can be cultivated. The above authors emphasise that the popular belief that sport builds character does not fit well with today's criticism of competitive sport and that special attention should be paid to individual differences and the characteristics of the populations involved.

For any child or adolescent, sport as a way of integration can be used to promote and sustain an active and healthy lifestyle. Visek et al. (2015) have developed the fun integration theory (FIT), which is a multi-theoretical, multidimensional and stakeholder-derived framework.

In the conclusions of a study about migrants, Lüschen (1984) suggests that sport and highperformance sport compensate for status inconsistency and that social integration beyond social classes is possible through sport.

Sherry (2010) shows that marginalised groups, in this case, those experiencing homelessness, are largely excluded from participation in and the benefits provided by sport programmes and events. The study demonstrates the role that sport programmes can play in the (re-)engagement of marginalised people within the broader community.

Haudenhuyse (2017) states that one aspect of sport that is often highlighted is its potential to mitigate the social exclusion processes experienced in different areas of life. The issue brings 
together a unique collection of international researchers and papers approaching relations, contexts, experiences and assumptions about young people who are at risk of social exclusion.

For children with disabilities, six categories of outputs emerged from sport participation: getting new friends, learning, strengthening one's physique, becoming someone, experiencing nature, and having a good time (Kristén et al., 2002). Hassan et al. (2012) emphasise the positive impact of sport on the integration and inclusion of athletes participating in the Unified Sports programme. Unified athletes demonstrated an increase in social self-perception, which remained unchanged in the traditional athletes (Riggen \& Ulrich, 1993).

\section{Using team sport to reduce social exclusion}

Defining the notions of game and team sport has aroused the interest of many specialists. Synthesising their ideas for our study regarding the implemented project, we consider it useful to separate the following notions:

Game - a predominantly physical and emotional complex activity carried out spontaneously according to predefined rules, for recreational, sporting or social adaptation purposes.

Team sport - a sequence of exercises specific to a certain sport practised as a game with an object that has specific dimensions, through which two teams or two opponents compete against each other according to a certain set of rules and regulations.

Play is a fundamental activity for pre-schoolers, who continue to remain interested when they are in school. During school, children prefer to have the playful behaviour to which they are used. Their motivation for playing is strong. Due to this, the learning activity organized through lessons needs to be highly attractive and take into account the impulses, behaviours and psycho-pedagogical aspects of the child.

Dynamic game is a variant of the play activity that is based on different motor skills; it is motivated by a theme, respects certain rules and has a specific purpose. Motor skills have the following components: walking, running, crawling, climbing, speed drills, coordination, ball drills etc., all of them executed in different formations, forms and combinations of structures.

Cerghit (1976) places the didactic game in the category of learning methods based on action, in which playful behaviour contains a complex activity that aims for objectives specific to a certain context in conditions of competition, cooperation and interdependency.

Practice has proven the applicability of the game spirit to the child's activities based on physical exercise and dynamic/movement games.

Dynamic game is a concrete value in the direction of both motor development and its use as an efficient means of learning a sport. As such, this form of learning by playing should not be neglected and can be used as much as necessary. The low number of rules allows easily reaching the established pedagogical objectives in a pleasant manner.

Teaching based on movement games helps children discover how their bodies work when in contact with an object or opponent. Such aspects make these games indispensable to children, necessary to adolescents and useful to adults because, during the activity, the participants come into contact with the main components of sports:

- Choice (direction, distance, speed, pace, etc.)

- Decision (which appears when initiating an action)

- Action (which improves motor skills) 
Besides their physical benefits and the fact that children learn by playing, dynamic games develop all social functions that are the foundations of living in a community:

- Team spirit and group responsibility

- Following the rules, social cohesion, self-esteem and respect for others

- Tolerance

- Equal opportunities

- Competition and fair-play spirit and rules of conduct

Dynamic games are variants of didactic games and, through their physical and motor character, operational objectives and the pleasure created for participants, they become efficient educational methods in the field of physical education and sport, with a pronounced role in fostering social inclusion.

In the development of the project, in the context of extracurricular physical activity, we consider interesting the point of view according to which physical education is a statutory area of the school curriculum concerned with developing the physical competence and confidence of students, as well as their ability to use these in order to perform in a range of activities (Department for Education and Employment [DfEE], 2000).

Regarding the type of sport practised, the findings of some studies (Nia \& Besharat, 2010) showed that team sport athletes scored significantly higher for agreeableness and sociotropy than individual sport athletes. Results obtained by Bruner et al. (2014) indicate the influential role that a cohesive sport team has on the personal development of young athletes.

Team sports seem to be more advantageous for the development of enjoyment and cohesion, which are both factors that positively impact the health outcomes of the intervention (Elbe et al., 2017).

In a study conducted by McCarthy et al. (2008) on 152 participants aged 8-15 years, team sport athletes reported significantly higher self-referenced competency, affiliation with peers, competitive excitement, positive parental involvement and enjoyment compared to individual sport participants.

\section{Education methods}

In the complex process focused on the education of children at risk of social exclusion through sports activities, certain physical and motor objectives are being targeted. These objectives are related to learning, consolidating or improving knowledge and motor skills, developing physical attributes, as well as to social objectives that mainly aim to facilitate the integration of children into small, medium and large social groups.

Among the most important functions of the methods used to teach through sports activities, we would like to remind the following:

- Communication - transmitting new knowledge, abilities and attitudes

- Cognitive - learning new knowledge, abilities and attitudes

- Normative - organizing, directing and continuously correcting the teaching process

- Motivational - arousing and keeping students' interest, curiosity and desire to know and act

- Operational-instrumental - as an intermediary between the student and the content unit. 
The teacher is a representative of the science that mediates access to knowledge by means of certain methods.

During the project, the researchers identified a series of general methodological requirements for teaching children at risk of social exclusion:

- Teaching will be correlated with the physiological and psychological particularities of the age of childhood.

- Adapting the playing space to the needs and abilities of the participants.

- Teaching will be universal, regardless of height/size.

- The emphasis will be on developing fundamental motor skills (walking, running, jumping, throwing etc.) and less on physical qualities.

- From a practical point of view, the emphasis will be on creating and developing the feeling of belonging to a group and combativeness.

- Teaching can be done in mixed groups (boys and girls) because, at this age, the level of skill development is relatively similar.

- As a main teaching method, it is recommended to use games and even role-playing games while developing motor skills.

- The use of varied materials or construction of special equipment.

- The teacher will ensure that each child takes pleasure in the game and will encourage each child's personal initiative to apply certain motor skills and specific movement patterns.

- Modifying the rules and regulations of the game and adapting them to the established goals.

- Reducing the intensity of physical contact between participants as much as possible.

- Teaching the students simple notions of rules and regulations and explaining the performance that can be achieved at their age will help capture their interest.

- Refereeing will be done according to the needs and abilities of the participants.

- Perceptual motor learning is recommended.

- Evaluation will be done individually/for each child through specific tests but mostly through competitions.

- Conscious and creative attitudes should be encouraged, based on child-child and childteacher dialogue and communication.

For methodological assignments, the following points are a priority:

- The coordinating teacher, as an educator, should be able to establish optimal relationships between the sport they teach and their students (participants, regardless of their condition).

- These relationships should be balanced, building the teaching process according to the age, gender, development and abilities of the students, as well as according to the place where the activity takes place, the available materials and the working conditions.

\section{Methodology}

The research in the first year of the project, which was done by experts in implementing team sports, aimed to identify relevant aspects for the application of the means and methods specific to team sports in order to optimise the implementation methodology. 
For this, a questionnaire was given to the teachers working in the 8 implementation regions, so that a correct selection could be made for the activities and means of teaching suitable for the target group participants.

The questionnaire was distributed to 15 teachers involved in the project, out of a total of 16 . The questions were as follows:

1. What verbal methods do you use to teach the target group? The response can be selected from a list of 5 verbal methods.

2. What intuitive methods do you use to teach the target group? The response can be selected from a list of 5 intuitive methods.

3. What practical methods do you use to teach the target group? The response can be selected from a list of 7 practical methods.

4. What pedagogical approach do you use to teach the content presented in the implementation methodology? The response can be selected from a list of 6 pedagogical approaches.

5. How much do you use the following aspects of teaching and learning when you teach the content of team sports? The response can be selected from a list of 15 methods of organizing the content.

6. What teaching materials/resources do you use when working with the target group? The response can be selected from a list of 5 types of teaching materials/resources.

7. Where do you usually find out about the teaching resources you use during lessons? The response can be selected from a list of 7 means of information.

8. What teaching materials/resources would you like to use but do not have access to? The response can be selected from a list of 14 teaching materials with a high level of utility in team sports.

9. In your opinion, does teaching of the content according to the project methodology have a positive impact on reducing social exclusion? The response can be selected from a list of 8 expected effects of project implementation.

10. In your opinion, considering the target group and available material conditions, which sport game has a positive impact on reducing social exclusion? The response can be selected from a list of 4 team sports that are predominantly implemented in the schools participating in the project.

For each of the above-mentioned questions, participants may also give different responses than those provided in the list.

\section{Results}

The results of the questionnaire survey were separately interpreted for each question, considering the number of responses and the percentage from the total number recorded for each item. 
What verbal methods do you use to teach the target group?

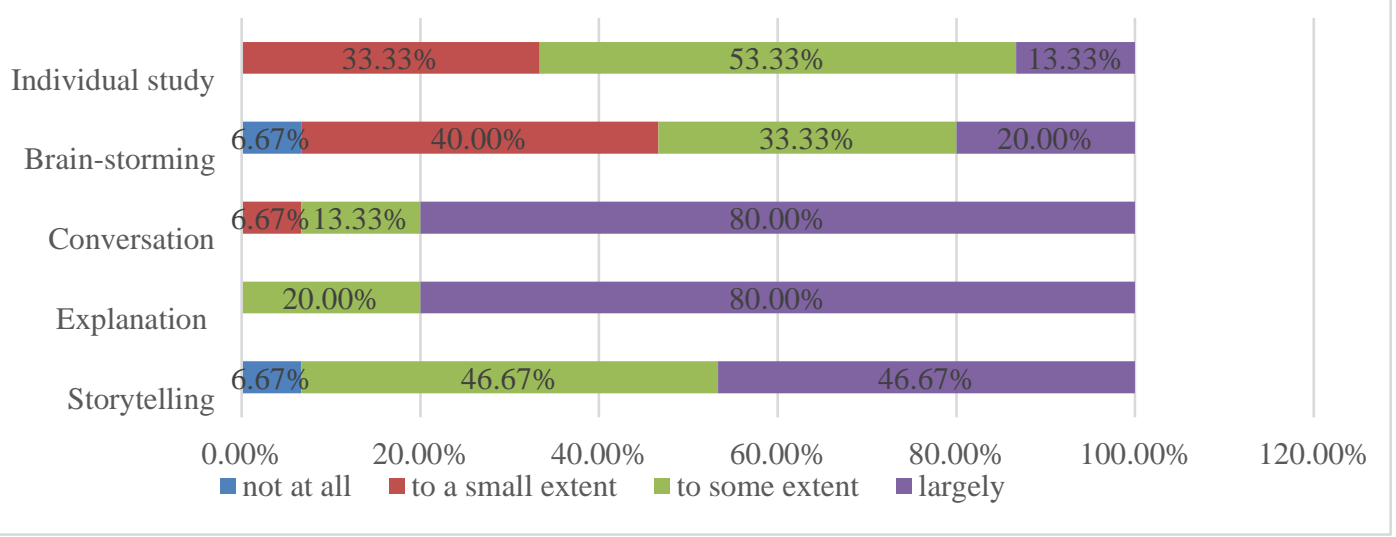

Figure 2. Results for the verbal methods used

Regarding the verbal methods used by the surveyed teachers (Figure 2), $80 \%$ of them mostly use explanation and conversation. Storytelling adapted to the level of understanding of the students is somewhat used by $46.67 \%$ of respondents. Brainstorming and individual study are used by $40 \%$ and $33.33 \%$, respectively.

Along its 4 years, the project requires the development of aspects that can influence students in terms of how to enhance their ability to interact with other members of the group, as well as to form the habit of maintaining their activity specific to individual sport training. For this, we consider it appropriate to raise the level of using brainstorming and individual study so that students can better develop for socialisation and exchange of ideas and nurture their ability of independent and correct practice of sports activities.

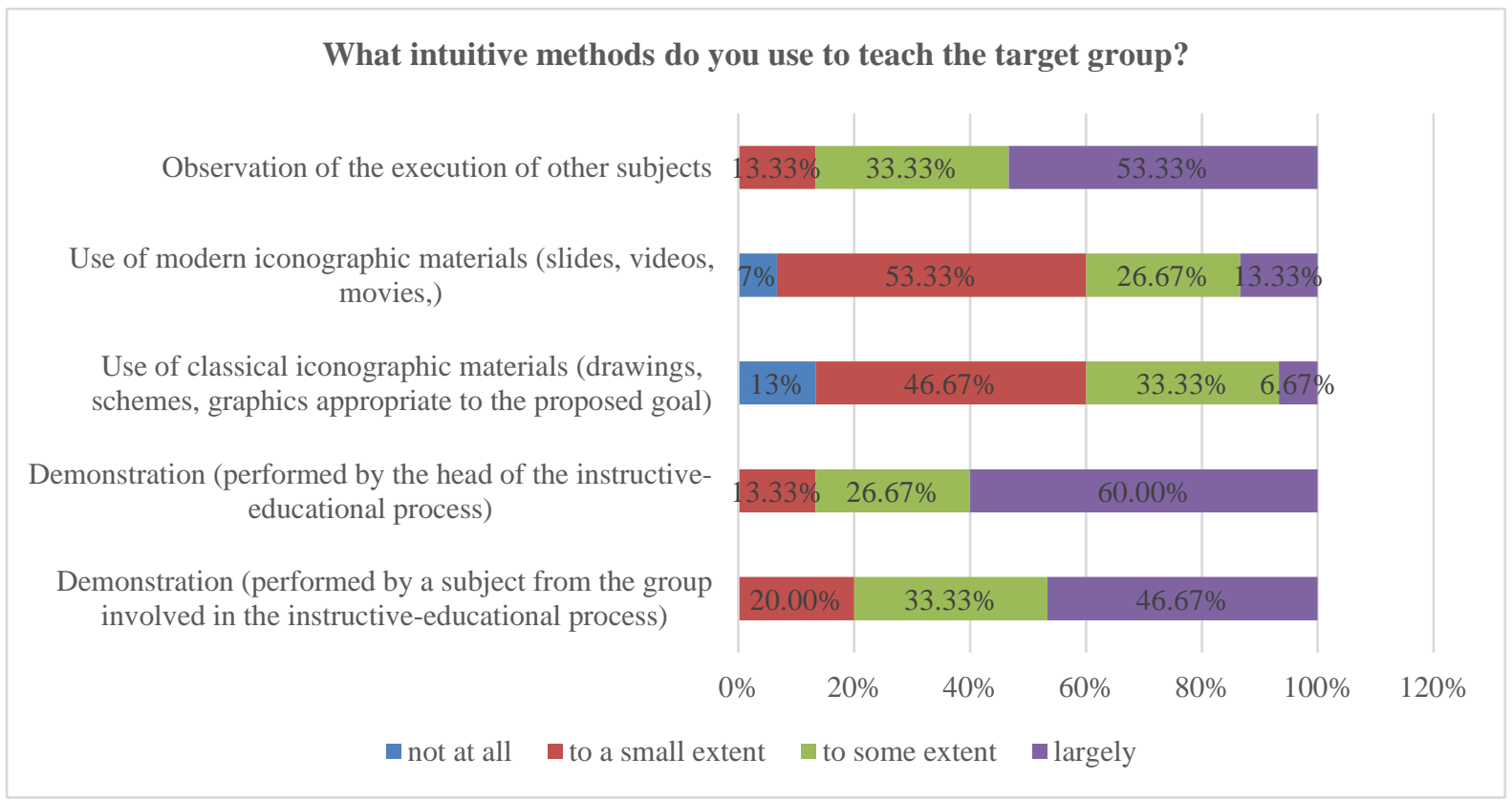

Figure 3. Results for the intuitive methods used 
From the data analysis (Figure 3), the most used method is direct demonstration, with a popularity of $60 \%$; it is classically used in physical education and sport. In the context of this project, the method is convenient because the teacher can promptly adapt the demonstration to the particularities of the group. Also, the teacher becomes a personal model and a learning facilitator - the main features of the student-centred approach.

It is gratifying that placing the observation of other students' exercise at a small distance draws attention to the other colleagues of the group.

Regarding indirect demonstration - performed by one of the group members within the same student-centred approach, this is a good way to delegate the teacher's authority to a student. Using this method can increase students' self-esteem, especially if the teacher has the pedagogical skill to distribute demonstration tasks to all students, in turn.

We notice that the least used method refers to modern technology, like using videos, slides, etc. On the one hand, this is because of the learning space (playground, sport hall) and, on the other hand, because the schools involved in this project are not very well equipped from this point of view.

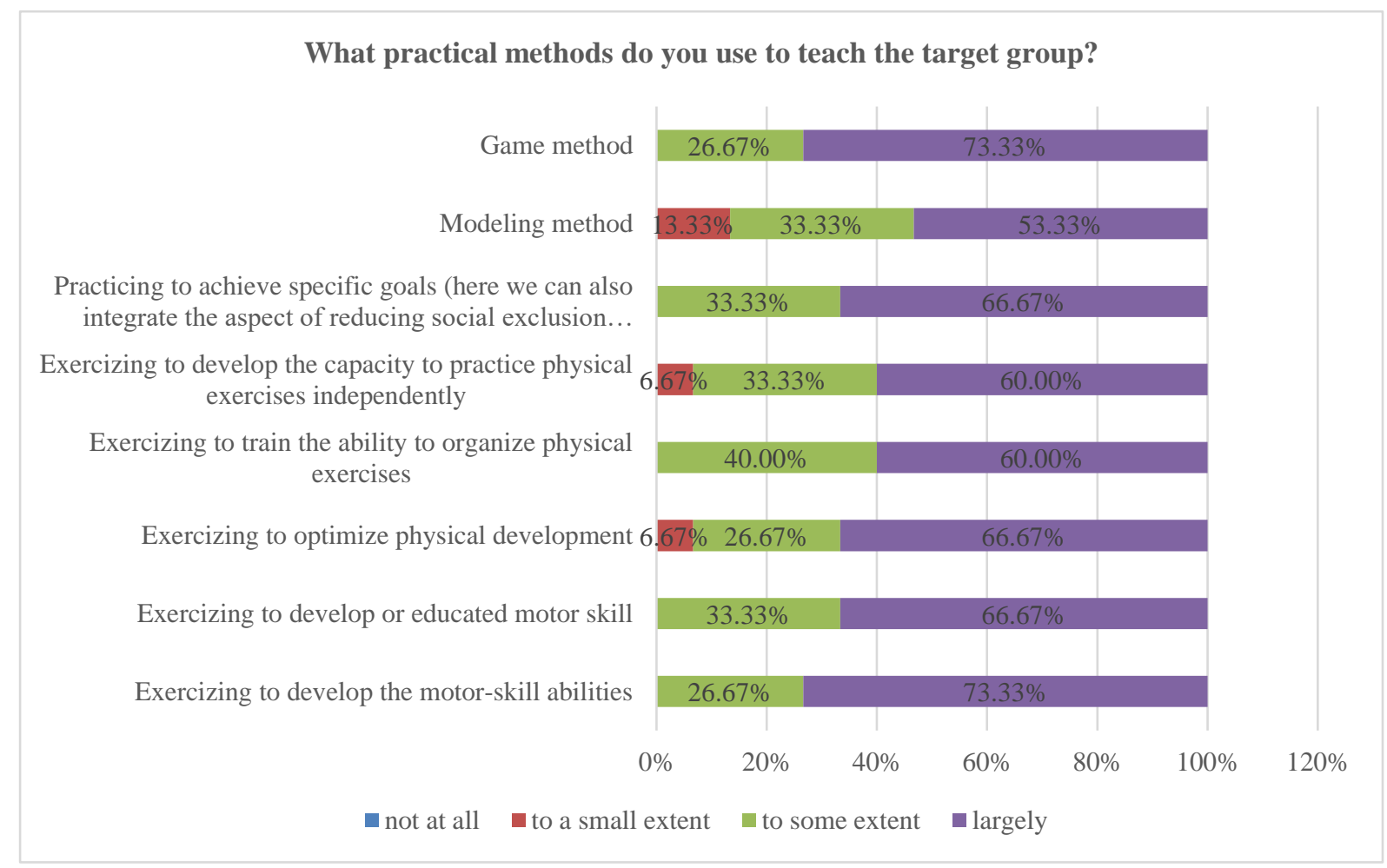

Figure 4. Results for the practical methods used

Regarding the practical methods used (Figure 4), it is good that the teachers' preference is to use games and practice to develop motor skills. These two methods are interconnected because the game involves a series of skills. In team sports, these specialised skills form the technique of the game and ensure participation and integration into a group with a common goal. A game-based learning method is very suitable for the sample group, in accordance with age as well. 
It is convenient that independent practice is less used, given that the purpose of the project is integration, and this is better achieved through group activities. Forming the ability of independent practice of the exercise is an objective of the physical education curriculum and it is suitable to complement this with the project-specific objectives.

The variation in opinion regards the modelling method, which was to be expected, considering that this is mostly used in performance sport where the basic parameters are those specific to the competition.

We have noticed that absolutely every method is used, none is omitted.

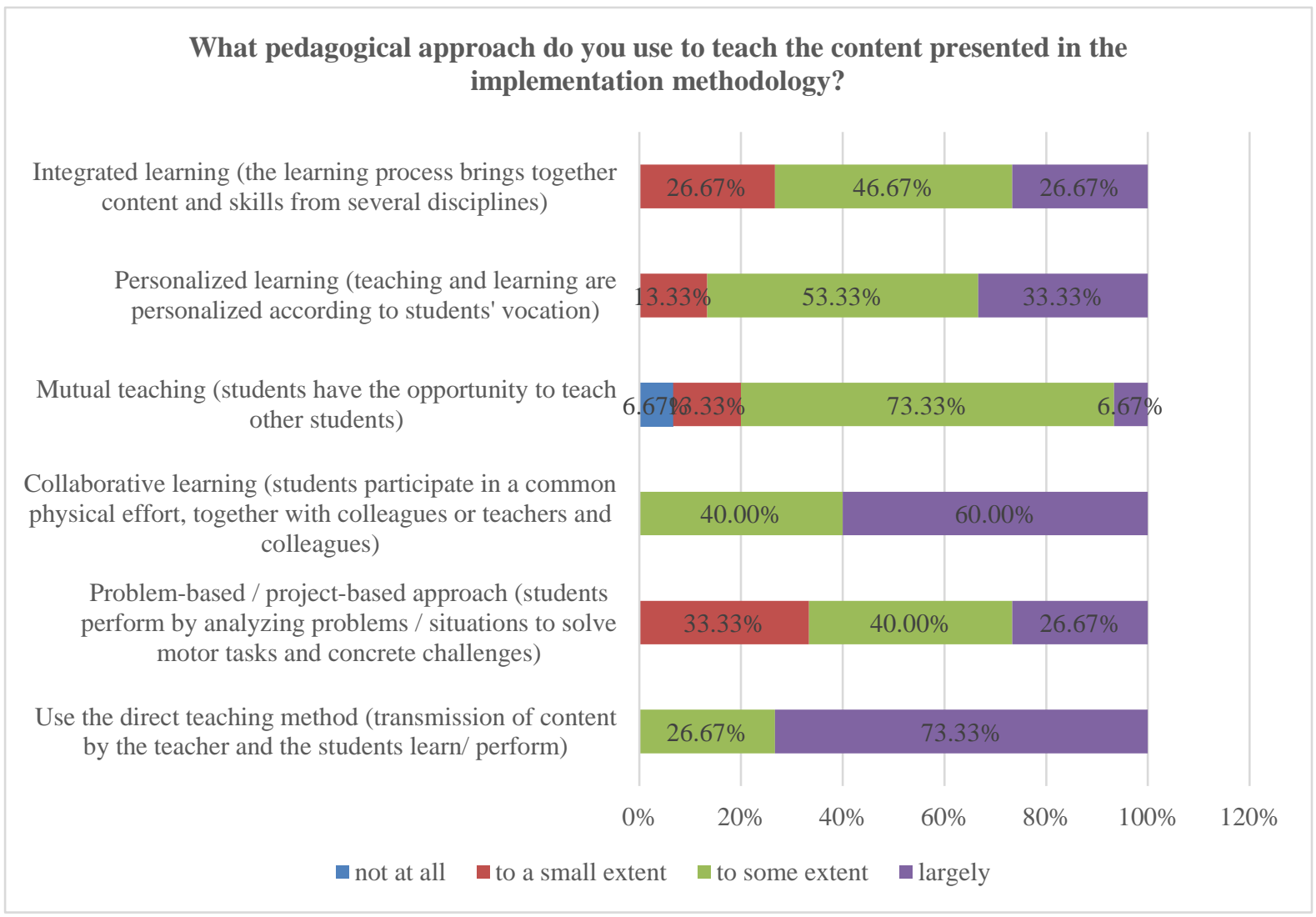

Figure 5. Results for the pedagogical approach used

From a pedagogical approach perspective (Figure 5), there are various options for use when teaching in the field of sports games, depending on the target group and the aim pursued.

Integrated learning is used by $46.67 \%$ of respondents. These teachers manage to corelate certain motor skill circumstances with the specific content of other subjects in the curriculum.

Personalised learning is used to some extent by $53.33 \%$ of respondents and largely by $33.33 \%$ of them.

In the development of the project context, we consider mutual teaching to be very important, and it is currently used to some extent by $73.33 \%$ of respondents. For the next years of the project, we believe that preponderantly using this teaching method is absolutely necessary. This might have a positive impact on social adaptation and integration into small groups.

Responses to this question highlight that $60 \%$ of teachers largely use collaborative learning. 
Considering the specific features of team sports - solving motor skill circumstances through in-group collaboration, this approach perfectly corresponds to the purpose of the project and the specifics of teaching team sports.

Solving concrete challenges and motor-skill tasks specific to team sports is not much used by teachers: $26.66 \%$ largely, $40 \%$ to some extent, $33.33 \%$ to a small extent. Raising the frequency of using this pedagogical approach can be a landmark in optimising project implementation methodologies, given that this approach can increase self-esteem levels in middle-school students.

The most used pedagogical approach is the direct teaching method for information transmission: $73.33 \%$ of respondents have stated that they largely use this approach.

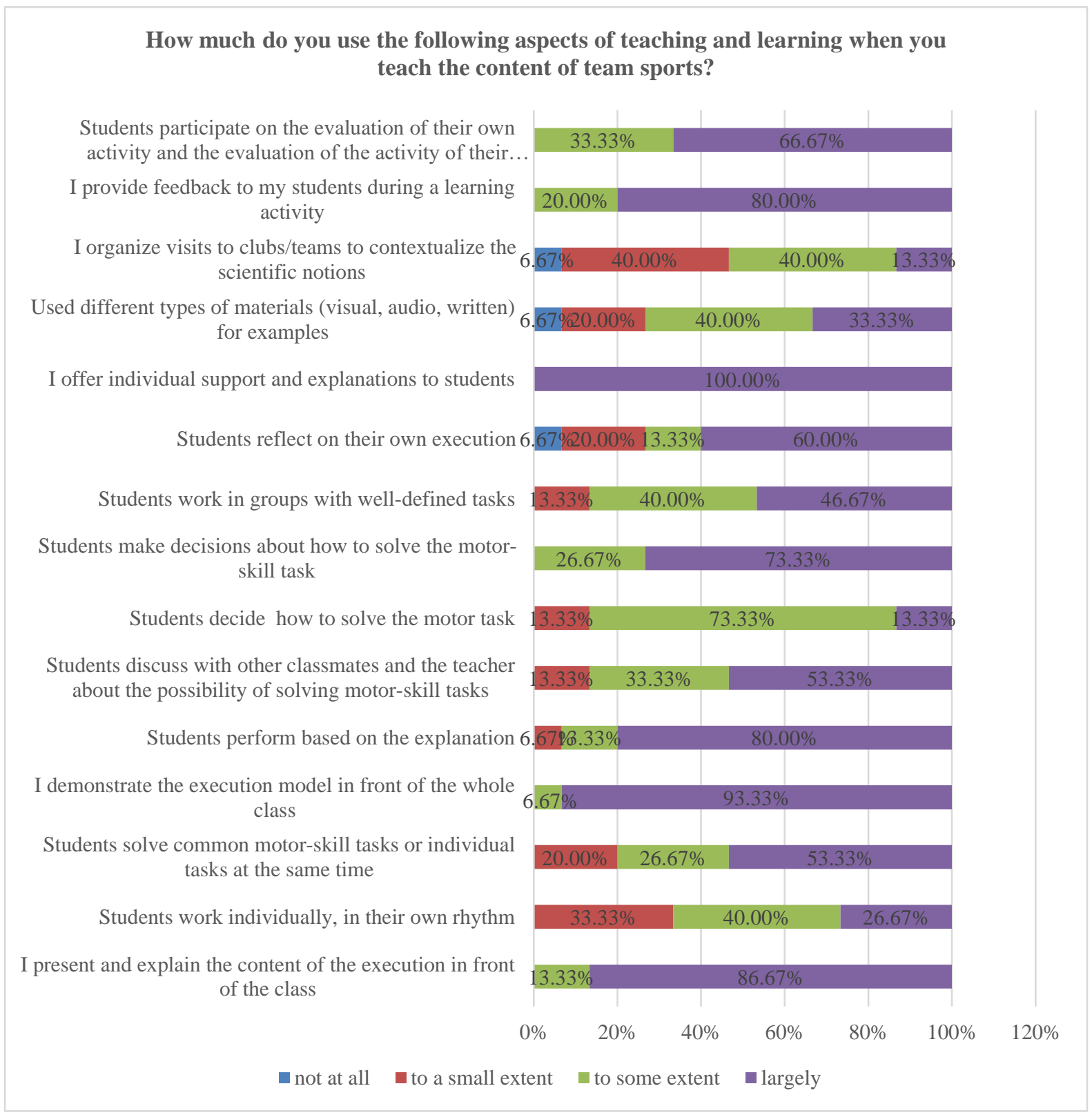

Figure 6. Results for the teaching and learning aspects used in team sports 
Another question was about the aspects of teaching the content of sports games (Figure 6). The collected responses highlighted the teachers' level of involvement in the activity. We notice that teachers use to a large extent (over 50\%) students' self-assessment and their colleagues' assessment of the activity, providing them with feedback during practice as well as permanent individual support and explanations, group work with well-defined tasks and the execution of specific skills based on explanations. Also, the teacher presents, explains and demonstrates in front of the entire class.

Responses to the questionnaire also show that students are given "to some extent" the possibility to decide on how to solve a certain motor-skill task, which has effects on developing their creative thinking.

We can conclude that currently visiting clubs/sports teams or using different types of materials to exemplify the content do not represent frequent approaches in the practice of teachers participating in the project.

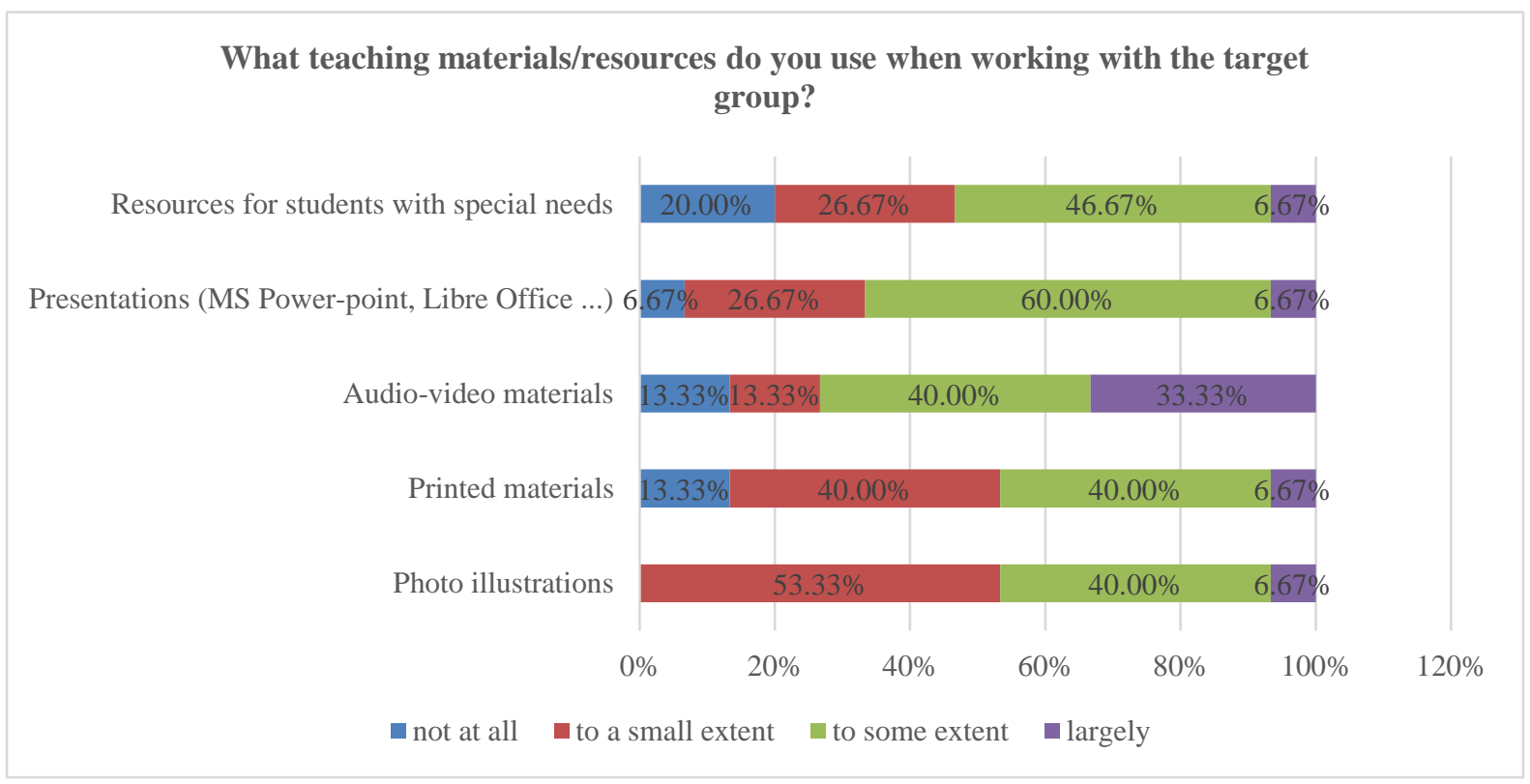

Figure 7. Results for the teaching materials/resources used

Responses to the question about the teaching/learning resources that complement the verbal, intuitive and practical/methodological aspects of teaching (Figure 7) show that the mentioned resources are used to some extent (40\%-60\% of respondents) or to a small extent $(13.33 \%$ $53.55 \%$ of respondents).

Audio/video materials are largely used by $33.33 \%$ of respondents and not at all by $13.33 \%$ of them.

Photo illustrations are used to a small extent by $53.33 \%$ of teachers. 


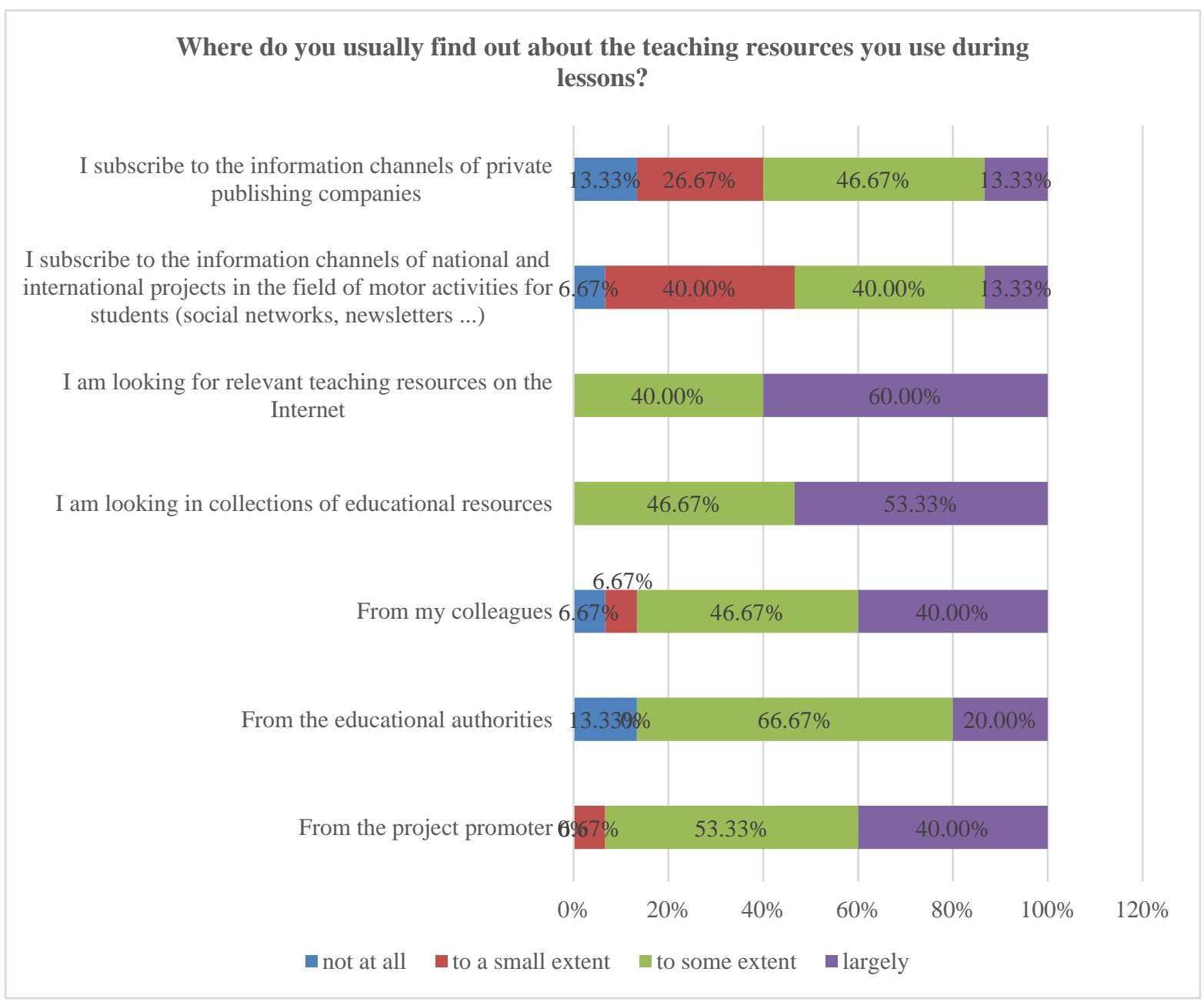

Figure 8. Results for the teacher knowledge about the materials/resources used

Teacher knowledge about the materials/resources used (Figure 8) shows that they preponderantly use the Internet for information: largely, $60 \%$ search for didactic resources in the online environment, and $53.33 \%$ in collections of educational resources.

Educational authorities and project promoter are considered to some extent as information sources by $66.67 \%$ of teachers and $53.33 \%$, respectively.

Another source of information is represented by the respondents' colleagues, $40 \%$ saying that they largely use this type of information, while $46.67 \%$ use it to some extent. 
What teaching materials/resources would you like to use but do not have access to?

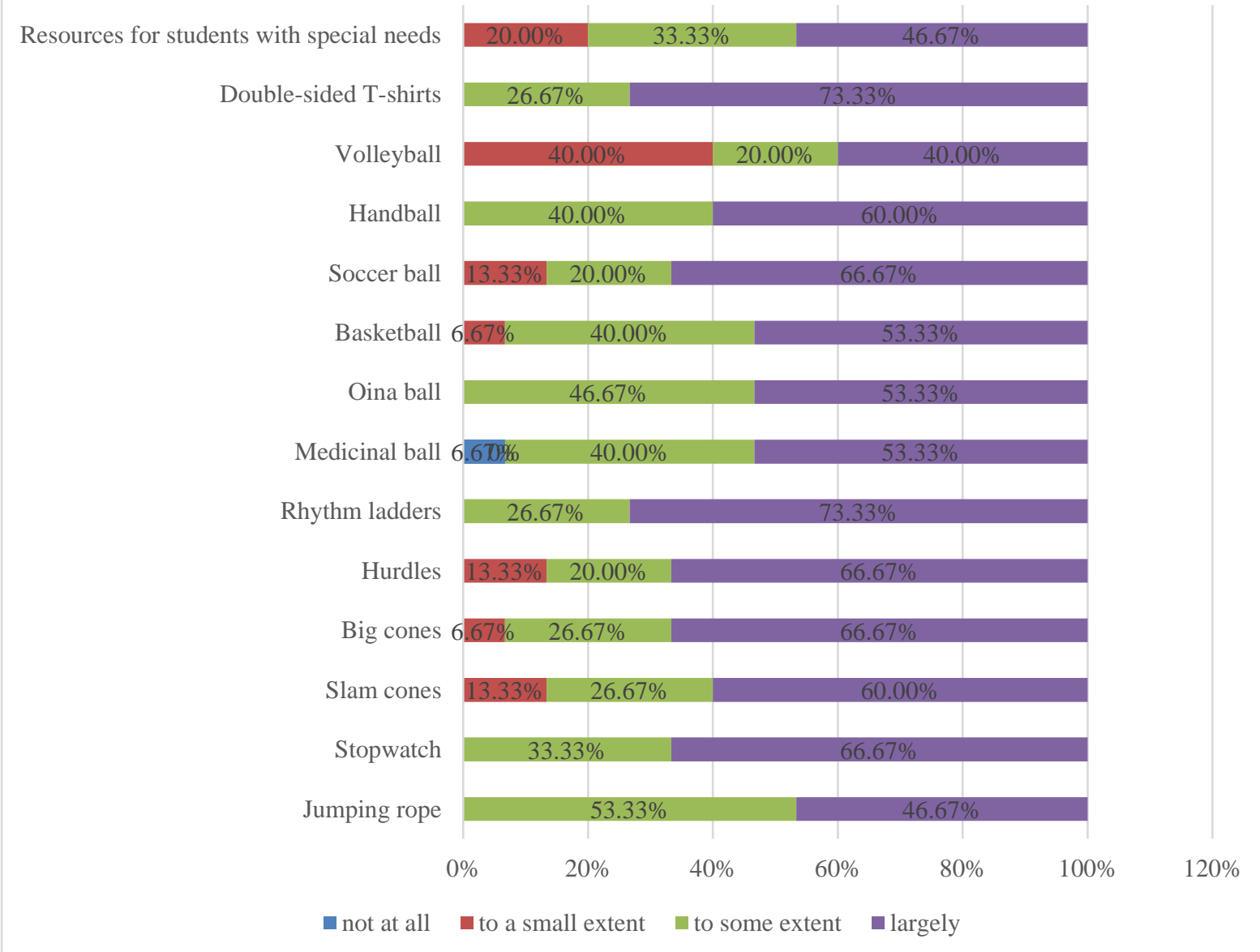

Figure 9. Results for the necessary teaching materials/resources

Regarding teaching materials thought to be necessary for implementing the methodologies developed during the project (Figure 9), teachers largely considered (between $50 \%$ and $73.33 \%$ ) that 11 of the listed materials would be useful. Among them, the stationary ladder was considered to be largely necessary by $73.33 \%$ of teachers.

The results highlighted a correct estimate from the project managers to purchase these materials in order to support the expected activities with team sports content. 
In your opinion, does teaching of the content according to the project methodology have a positive impact on reducing social exclusion?

Students adapt more easily to new situations

Students develop their ability to socialize

Students develop critical thinking

Students remember more easily what they learned

Students understand easier what they are learning

Students feel more independent in the act of learning.

Students undergo sustained effort during lessons

Students focus more on the act of learning

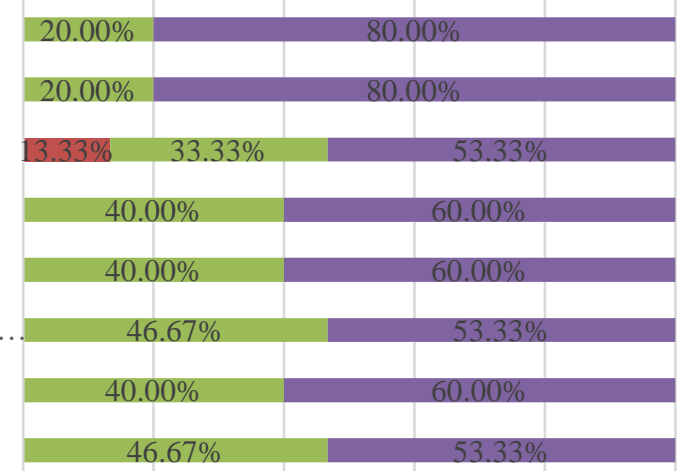

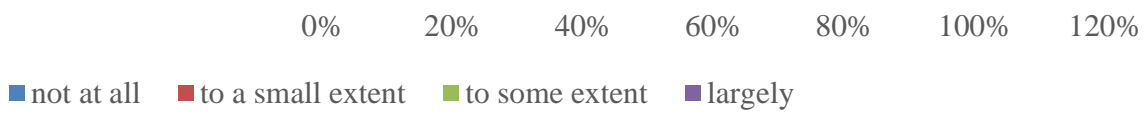

Figure 10. Results for the impact of project implementation on reducing social exclusion

Another question investigated teachers' opinions regarding the effects of the methodology on reducing social exclusion (Figure 10).

Developing the ability to adapt to new situations and the ability to socialise are "largely" considered to be the benefits of the project by $80 \%$ of respondents and "to some extent" by $20 \%$ of them.

Percentages over 50\% are recorded for 5 other questions and it is considered that the project largely determines these effects.

It is also considered that intense efforts are largely provided (46.67\%), but this does not represent an objective of the implemented project. 


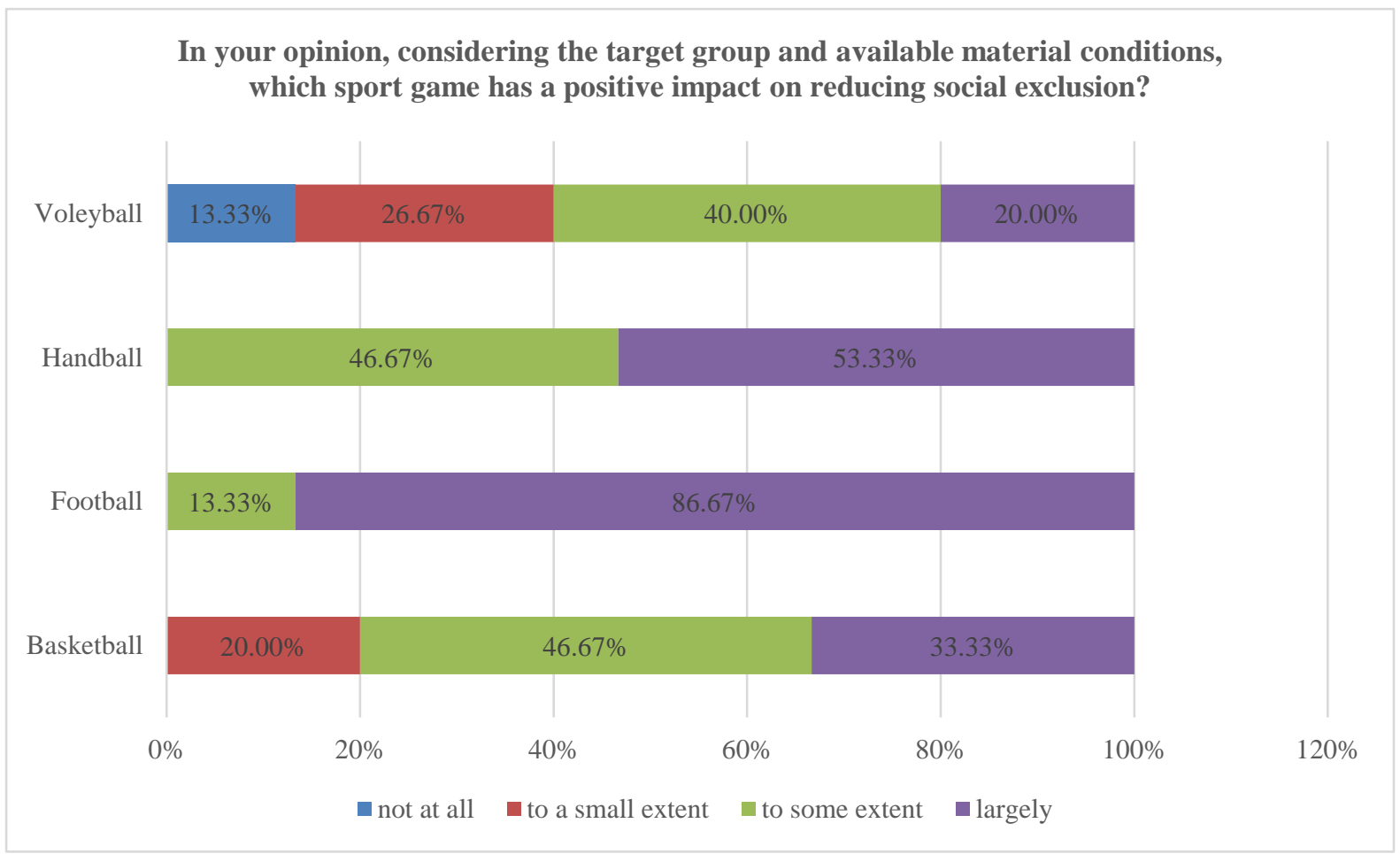

Figure 11. Results for the impact of sports games implemented in the project

The effects of team sports on reducing social exclusion (Figure 11) indicate that football is the main sport used by teachers to educate the target group. This is conditioned, of course, by the material resources necessary to practise certain sports disciplines.

Handball and basketball are also largely used $-53.33 \%$ handball, $33.33 \%$ basketball. Some respondents also said that they used both handball and basketball to some extent $-46.67 \%$ for both.

We consider volleyball to be the least accessible due to the current equipment available in the schools that are included in the project. It is largely used by $20 \%$ of respondents and not at all by $13.33 \%$ of them.

\section{Discussion}

The benefits of project implementation in terms of reducing the risk of social exclusion is also confirmed by previous studies conducted by Lüschen (1984), Elling et al. (2001), Krouwel et al. (2006), Sherry (2010), Hatzigeorgiadis et al. (2013).

The information from the Ministry of Education and Research shows that, in Romania, the population most exposed to school dropout is represented by the $5^{\text {th }}$ grade students.

Responses to the questionnaire indicate the practical ways for the project teachers to apply the teaching methods, the information and material resources that are necessary in order to apply the teaching methodology in the field of team sports, as well as the impact of the methodology application on reducing social exclusion.

Responses to the questionnaire applied have highlighted the following issues: 
- Regarding verbal methods, explanation and conversation are the most used methods by teachers: from the point of view of project development, we consider it beneficial to use brainstorming and individual study. These methods stimulate personal development, as well as the ability to independently practise physical activities.

- The intuitive method mostly used by teachers is demonstration, in which the teacher is the model and learning facilitator. Part of the methods used is also indirect demonstration executed by a student.

- Among the practical methods, the most used are the game method and exercising to develop motor skills.

- Regarding pedagogical approaches, the most used is the direct approach in which transmitting the teaching content determines a certain acquisition from a motor skill perspective. As such, we consider it opportune to reorganize the pedagogical approach system of the teachers directly involved in the project towards the frequent use of approaches that push the student to get involved in solving challenges either individually or in group.

- Regarding teaching aspects, we notice the teachers' preference to lead and actively get involved in the progress of sports-games specific teaching, but also some intention of offering students the possibility to get involved in aspects such as leading and activity evaluation.

- From a project development point of view, the pedagogical approaches that involve the students' active participation in practical activities can determine their awareness of the execution models and the efficiency of individual and group work. This also subjects them to the effort of solving different situations and to permanent evaluation and self-evaluation.

- The resources to teach the target group indicate that video materials are mostly used. Correlating this with the responses regarding intuitive methods, we conclude that direct and indirect demonstration are preferred by teachers to the detriment of audio-video materials.

- Responses show that the teachers' main means of information are the Internet sources, discussion with colleagues, as well as information from the authorities and project promoter.

- Investigation of the material resources available in schools, which are necessary for the progress of activities proposed in the project, indicates, on the one side, the acute need for further equipment and, on the other hand, the need for a correct estimate of purchases within the project.

- The effects identified by teachers following the implemented methodology indicate an increase in students' ability to adapt to new situations and in their socialising abilities. All other aspects that facilitate student integration gather a percentage of over $53.33 \%$.

The research shows that practising team sports depends on the material conditions and the infrastructure available for the teacher during the lesson. Unsurprisingly, football is the most practised team sport.

\section{Conclusion}

Project implementation will lead to: developing and integrating the model through sport dedicated to children and youth at risk of social exclusion; creating a methodological and operational infrastructure to support the long-term integration of vulnerable children and youth in the educational system and communities to which they belong; raising awareness of the importance of education; creating a group of experts to ensure the sustainability of the project. 
Additionally, communication and awareness activities addressed to the communities aim at ensuring sustainable results. Developing a public policy is also an important outcome of the project because, in this case, the public policy is adopted by the competent authorities, and therefore the project outcomes will be multiplied and supported in the long term.

From the perspective of using teaching methods, the questionnaire applied has highlighted the following aspects:

- Verbal methods are effective in stimulating personal development, as well as the ability to independently practise physical activities.

- In our opinion, the intuitive method has an even greater influence in raising self-esteem and assuming responsibility and authority.

- According to us, the use of practical methods is justified in the context of the specific content of team sports.

Regarding pedagogical approaches, the direct teaching method can positively influence the students' ability to integrate into small groups represented by sports teams, leading in turn to a positive transfer of attitude towards the students' social activity.

Using video materials can open up a new perspective for students in practising sports games, raise their ability to focus, as well as develop their analysis skills and critical thinking.

The endowment of schools in disadvantaged areas does not allow the practical activity to be carried out at a satisfactory level so as to ensure increased efficiency. It is absolutely necessary to purchase sports equipment to ensure the development of activities at an optimal level.

\section{References}

Bruner, M. W., Eys, M. A., Wilson, K. S., \& Côté, J. (2014). Group cohesion and positive youth development in team sport athletes. Sport, Exercise, and Performance Psychology, 3(4), 219-227. https://doi.org/10.1037/SPY0000017

Cerghit, I. (1976). Metode de învățământ [Teaching methods]. București: Editura Didactică și Pedagogică.

Department for Education and Employment (DfEE). (2000). Physical education: The National Curriculum for England and Wales. London: DfEE/Qualifications and Curriculum Authority.

Dragnea, A., Bota, A., Teodorescu, S., Stănescu, M., Șerbănoiu, S. \& Tudor, V. (2006). Teoria şi didactica educației fizice şi sportului [Theory and didactics of physical education and sport]. București: FEST.

Elbe, A. M., Wikman, J. M., Zheng, M., Larsen, M. N., Nielsen, G., \& Krustrup, P. (2017). The importance of cohesion and enjoyment for the fitness improvement of 8-10-year-old children participating in a team and individual sport school-based physical activity intervention. European Journal of Sport Science, 17(3), 343-350. https://doi.org/10.1080/17461391.2016.1260641

Elling, A., De Knop, P., \& Knoppers, A. (2001). The social integrative meaning of sport: A critical and comparative analysis of policy and practice in the Netherlands. Sociology of Sport Journal, 18(4), 414-434. https://doi.org/10.1123/ssj.18.4.414

Hassan, D., Dowling, S., McConkey, R., \& Menke, S. (2012). The inclusion of people with intellectual disabilities in team sports: Lessons from the Youth Unified Sports Programme of Special Olympics. Sport in Society, 15(9), 1275-1290.

https://doi.org/10.1080/17430437.2012.695348 
Hatzigeorgiadis, A., Morela, E., Elbe, A. M., Kouli, O., \& Sanchez, X. (2013). The integrative role of sport in multicultural societies. European Psychologist. https://doi.org/10.1027/1016-9040/a000155

Haudenhuyse, R. (2017). Introduction to the issue "Sport for social inclusion: Questioning policy, practice and research”. Social Inclusion, 5(2), 85-90. https://doi.org/10.17645/si.v5i2.1068

Kristén, L., Patriksson, G., \& Bengt, F. (2002). Conceptions of children and adolescents with physical disabilities about their participation in a sports programme. European Physical Education Review, 8(2). https://doi.org/10.1177\%2F1356336X020082003

Krouwel, A., Boonstra, N., Duyvendak, J. W., \& Veldboer, L. (2006). A good sport? Research into the capacity of recreational sport to integrate Dutch minorities. International Review for the Sociology of sport, 41(2), 165-180. https://doi.org/10.1177/1012690206075419

Lüschen, G. (1984). Status crystallization, social class, integration and sport. International Review for the Sociology of Sport, 19(3-4). https://doi.org/10.1177\%2F101269028401900307

Marivoet, S. (2014). Challenge of sport towards social inclusion and awareness-raising against any discrimination. Physical Culture and Sport. Studies and Research, 63(1), 3-11. https://doi.org/10.2478/pcssr-2014-0017

McCarthy, P. J., Jones, M. V., \& Clark-Carter, D. (2008). Understanding enjoyment in youth sport: A developmental perspective. Psychology of Sport and Exercise, 9(2), 142-156. https://doi.org/10.1016/j.psychsport.2007.01.005

Nia, M. E., \& Besharat, M. A. (2010). Comparison of athletes' personality characteristics in individual and team sports. Procedia - Social and Behavioral Sciences, 5, 808-812. https://doi.org/10.1016/j.sbspro.2010.07.189

Riggen, K., \& Ulrich, D. (1993). The effects of sport participation on individuals with mental retardation. Adapted Physical Activity Quarterly, 10(1), 42-51. https://doi.org/10.1123/apaq.10.1.42

Sherry, E. (2010). (Re) engaging marginalized groups through sport: The Homeless World Cup. International Review for the Sociology of Sport, 45(1), 59-71. https://doi.org/10.1177/1012690209356988

Visek, A. J., Achrati, S. M., Mannix, H. M., McDonnell, K., Harris, B. S., \& DiPietro, L. (2015). The fun integration theory: Toward sustaining children and adolescents sport participation. Journal of Physical Activity and Health, 12(3), 424-433. https://doi.org/10.1123/jpah.2013-0180 